\title{
ANÁLISE DA DEGRADAÇÃO DE REAGENTES QUÍMICOS DE USO ACADÊMICO POR ESPECTROSCOPIA NO INFRAVERMELHO FTIR-UATR
}

\author{
Herbert Leite de Souza ${ }^{1}$ \\ Wellington Caetano Ferreira ${ }^{2}$ \\ Liu Yao $\mathrm{Cho}^{3}$ \\ Kumiko Koibuchi Sakane ${ }^{4}$
}

\begin{abstract}
Resumo: No meio acadêmico é comum a utilização de alguns reagentes com o prazo de validade fora do indicado pelo fabricante. Neste trabalho foram analisados reagentes no prazo de validade e após o prazo de validade coletados em laboratórios químicos, com intuito da criação de dados que comprovem a degradação gradativa dos mesmos após o vencimento da data prevista pelo fabricante, e quantificar a perda de pureza do reagente. Foi utilizada a técnica de espectroscopia no infravermelho FTIR-UATR e calculado as áreas de uma banda de referência para obtenção da porcentagem de degradação. Apesar do comportamento variado de cada reagente, as análises comprovaram que, numa visão geram, o uso de reagentes vencidos no meio acadêmico não representa grandes alterações nos produtos obtidos em reações químicas, pelo contrário pode representar uma economia financeira substancial.
\end{abstract}

Palavras-chave: Espectroscopia no infravermelho; Degradação; Reagentes químicos.

\footnotetext{
${ }^{1}$ Engenharia Química/ Universidade do Vale do Paraíba, Brasil. E-mail: her_leite@hotmail.com.

2 Engenharia Química/Universidade do Vale do Paraíba, Brasil. E-mail: well_poco@hotmail.com.

${ }^{3}$ Coordenador da Faculdade de Engenharia, Arquitetura e Urbanismo da Universidade do Vale do Paraíba, Brasil. E-mail: liu@univap.br.

4 Docente/Universidade do Vale do Paraíba, Brasil. E-mail: kumiko@univap.br.
} 